\title{
ARTE Y ARQUITECTURA EFÍMERA EN LOS FUNERALES REALES DE CÓRDOBA DEL TUCUMÁN
}

\author{
POR \\ Carlos A. Page \\ CONICET (Consejo Nacional de Investigaciones Científicas, Argentina) \\ Arquitecto y Doctor en Historia - Investigador adjunto
}

\begin{abstract}
RESUMEN
El tema sobre las honras y exequias reales ha tenido en las últimas décadas una particular consideración, sobre todo para las realizaciones efectuadas en las grandes capitales hispanoamericanas. Pero estas manifestaciones también aparecen en otras ciudades, como Córdoba del Tucumán, donde los jesuitas establecieron la primera universidad argentina. Desde su fundación (1573) dependió del virreinato del Perú y luego del Río de la Plata cuando fue designada cabecera de la gobernación homónima (1785). En el devenir de dos siglos de historia fue testigo de una serie de celebraciones luctuosas reales de las que han quedado escasos testimonios documentales y que pretendemos rescatar en este artículo. No se han conservado de Córdoba las excelentes representaciones gráficas de túmulos como los de Lima o México, pero sí una serie de documentos que describen estos monumentos que fueron el mejor exponente de la arquitectura efímera de su tiempo. Son testimonios que reunieron sistemas de representación que permitieron exponer además de la arquitectura, la escultura, pintura y literatura que situaban al espectador frente a todas las expresiones artísticas que pudieran trasmitir el doloroso mensaje.
\end{abstract}

PALABRAS CLAVE: Funerales reales, Córdoba del Tucumán, túmulos reales, arquitectura efímera, arte y arquitectura

\section{ART AND EPHEMERAL ARCHITECTURE IN THE ROYAL FUNERALS OF CORDOBA DEL TUCUMÁN}

\section{ABSTRACT}

The subject on you honors them and exequies real has had in the last decades a particular consideration, mainly for the accomplishments conducted in the great 
Hispano-American capitals. But these manifestations also appear in other cities, like Cordoba del Tucumán, where the Jesuits established the first university in Argentina. From his foundation (1573) it depended soon on the virreinato of the Perú and of the Río de la Plata when was designated to head of the government (1785). In happening of two centuries of history it was witness of a series of real mournful celebrations of which they have been left little testimonies documentary and that we try to rescue in this article. The excellent graphical representations of tumuli have not been conserved of Cordoba as those of Lima or Mexico, but several documents that describe these monuments that were the best exponent of the ephemeral architecture of their time. They are testimonies that made meet systems of representation which they allowed to expose in addition to the architecture, the sculpture, painting and literature that located as opposed to the spectator all the artistic expressions that could transmit the painful message.

KEY WORDS: Real funerals, Córdoba del Tucumán, tumuli, ephemeral architecture, art, architecture

Recibido/Received 23-02-2008

Aceptado/Accepted 05-07-2008

La pompa fúnebre, el grande acompañamiento en los entierros y exequias, la magnificencia de los túmulos y mausoleos, sirve más para consuelo de los vivos que para alivio de los difuntos

San Agustín

\section{LAS FIESTAS CÍVICAS Y RELIGIOSAS}

Desde la creación de la Congregación de Ritos dispuesta en 1588 por el papa Sixto V, que regulaba el ejercicio del culto y el tratamiento de las causas de santos, hasta el decreto de 1789 de Carlos IV que imponía las fiestas obligatorias, tanto religiosas como civiles, se fue legislando cada detalle en su implantación, lo que demuestra el grado de importancia que progresivamente se le fue confiriendo.

La Plaza Mayor era el espacio urbano que concentraba las actividades de carácter cívico y religioso de la ciudad, donde se realizaban innumerables procesiones, destacándose la del santo patrono. Estos desfiles eran presididos por el estandarte o pendón de la ciudad que solemnemente llevaba el alférez real y concluían en una misa oficiada en la iglesia mayor. En este sentido tanto la iglesia como el Estado utilizaban la plaza como extensión de sus propias actividades internas, llevando hacia afuera una extroversión del culto y del monarca, sacralizando el espacio público. Los grandes atrios, el cementerio continuo a la iglesia, las procesiones y el vía crucis por la plaza demuestran esta actitud de la iglesia; al igual que la administración de justicia, los pregones y celebraciones reales, en el accionar del Estado. El protagonista siempre era el rey; aunque

Hispania Sacra, LXI

124, julio-diciembre 2009, 423-446, ISSN: 0018-215-X 
ausente, éste delegaba su autoridad en los representantes locales, que tomaban su papel ostentando un lujo y pompa propia de la realeza, produciendo un deslumbramiento en el pueblo que marcaba las jerarquías establecidas. No obstante la falta de la presencia física del rey era sustituida por su retrato, pintado por algún artista de cámara, que servía a los fines de veneración ${ }^{1}$.

Los actos públicos eran coronados con actividades populares, que giraban en torno a la diversión, muy apegada al pueblo español y clara herencia oriental. Juegos y esparcimientos públicos se desarrollaban desde las representaciones teatrales, romerías, caballos y toros, hasta los de carácter privado como los naipes, «trucos» (billar), «tablas» (dados), los bolos y el tejuelo. Como bien señala Bonifacio del Carril «desde los primeros tiempos de la vida colonial en las poblaciones de alguna importancia de la América española los fuegos de artificio y las corridas de cañas y de toros fueron entretenimientos obligados en las grandes festividades: juramento de un nuevo monarca, cumpleaños del rey, visitas de personajes importantes, nacimiento de un príncipe, día del santo patrono, y también, los domingos y días de fiesta» ${ }^{2}$. Esas eran las actividades que signaban la Plaza Mayor en las tierras de ultramar que poseía la Corona. Se desarrollaban en forma bastante continua, sirviendo incluso como instrumento político de sujeción sumamente regulado que sacaba a los vecinos de la monotonía diaria habitual por la que transitaban, haciéndolos participar a todos. Se conformó así un pueblo festivo que llevaba la alegría en el corazón como un reconocido sentimiento que respondía a su profunda vocación religiosa.

Las actividades cívicas y religiosas se desarrollaban dentro de un amplio calendario establecido por la autoridad eclesiástica y aquellas otras imprevisibles ligadas a determinados acontecimientos impuestos por el soberano como muertes, asunciones y visitas distinguidas que llegaban a la ciudad. Entre estas últimas podemos agregar algún triunfo militar en Europa, como la entrada a Barcelona que en 1653 fue festejada en Córdoba con grandes «demostraciones y regocijos», con fuegos de artificio y luminarias, tres días de toros y en el último el infaltable juego de cañas ${ }^{3}$.

Por esos días el ámbito urbano y sus protagonistas experimentaban cambios profundos en la ornamentación de edificios, limpieza de calles, colgaduras en balcones, vestimentas especiales, e incluso, en la ejecución de una arquitectura festiva construida para la ocasión. El resto del año y sólo de vez en cuando, se podía escuchar de los pregoneros (negro, mulato o indio) los bandos de gobier-

1 Ángel López CANTos, Juegos, fiestas y diversiones en la América española, Madrid. Editorial Mapfre 1992,p. 26.

2 Bonifacio Del Carril, La Plaza San Martín. Trescientos años de vida y de historia, Buenos Aires, Emecé Editores 1988, p. 31.

${ }^{3}$ Actas Capitulares (en adelante AC), Libro X, 1650-1663, Córdoba, 1953, p. 248. 
no, anuncio de almonedas y otras noticias de interés que igualmente eran impresos en afiches y fijados en las puertas del Cabildo. En este sentido, el artículo 18 del Bando de Buen Gobierno del gobernador del Tucumán don Juan Victorino Martínez de Tineo, del 15 de julio de 1749, expresaba que todos los habitantes de la ciudad al escuchar la «caja de guerra» debían acudir de inmediato a la Plaza Mayor para enterarse de lo que sucedía ${ }^{4}$.

La indumentaria de los actores alcanzaba no poca importancia en una sociedad estamental, cargando con toda la simbología que representaba. De tal manera que para las fiestas patronales los miembros del Cabildo secular se ponían la golilla, el adorno llevado al cuello, de lienzo plegado y alechugado. Este elemento fue prohibido en 1780 por provisión del gobernador Andrés Mestre, instrumento en el que también se dispuso cómo debía ser el traje festivo de calle:

\section{«el vestuario corto, o de militar, que llaman, de color negro, el que acostumbrará el Ayuntamiento y no otro»5.}

El ingrediente cívico de la acción religiosa era precisamente el acompañamiento del Estandarte Real, símbolo de la autoridad monárquica, que circulaba con el alférez real, casi siempre a caballo, acompañado por los vecinos y al toque de cajas y pífanos.

\section{Celebraciones Reales en CóRdoba}

Otro tipo de sucesos aconteció con relación a ciertos hechos de importancia ocurridos en España y más precisamente con referencia al monarca. De allí que surgieron una serie de celebraciones y fiestas, cuyo ámbito central fue la Plaza Mayor aunque compartida con la Catedral y el Cabildo, inseparables emblemas del poder hispano.

Estos acontecimientos reflejaron «el espíritu de vasallaje a la autoridad Real y la relación directa con formas de expresión religiosa» ${ }^{6}$. Efectivamente las ce-

\footnotetext{
${ }^{4}$ Archivo Histórico de la Municipalidad de Córdoba «Dr. Carlos A. Luque Colombres», Cabildo Documentos II, fs. 214-217.

${ }^{5}$ Archivo Histórico de la Provincia de Córdoba (en adelante AHC), Gobierno, caja 6, carpeta 4, leg. 72, cit. Javier Arnoldo BERDINI, «El traje académico y las colaciones de grado de los universitarios de Córdoba durante la época jesuítica (1622-1767)». Congreso Internacional Jesuitas 400 años en Córdoba, Córdoba, Universidad Nacional de Córdoba, Universidad Católica de Córdoba, Junta Provincial de Historia de Córdoba 1999, pp. 3-44.

${ }^{6}$ Ana María MARTíneZ DE SÁNCHEZ, «La regulación jurídica de lo cotidiano. Fiestas y celebraciones. Córdoba del Tucumán en el último tercio del siglo XVIII», X Congreso del Instituto Internacional de Historia del Derecho Indiano, Veracruz 1992, México, Escuela Libre de Derecho y Universidad Nacional Autónoma de México, 1995, p. 894.
}

Hispania Sacra, LXI

124, julio-diciembre 2009, 423-446, ISSN: 0018-215-X 
lebraciones reales, incluida la muerte, «sirven en América para reafirmar la pertenencia al Imperio español, para mantener viva la presencia del Monarca lejano y para fomentar los sentimientos de adhesión a uno y otro» 7 . La muerte suscita también el arribo de un nuevo y feliz reinado convirtiéndose en el corolario más lógico del amor por la vida. En este sentido el pueblo español hacía de la muerte un verdadero culto, precisamente por ese sentimiento de alegría innato que se expresa en los desmesurados adornos personales y en la no disimulada ociosidad. Aunque al americano, por más que llevara su rostro con gesto acorde a la circunstancia y rindiera las condolencias al funcionario a cargo como si fuera el principal deudo, le resultaba remota y casi mítica la figura real. Ciertamente la presencia del rey no gravitaba en la ciudad de manera directa, ni siquiera se tenía en claro la fisonomía del soberano, representado dudosamente en alguna moneda o lienzo. No pocos vecinos eran los que en ese luctuoso día descubrían las grandes virtudes del monarca en los elogios fúnebres.

El esplendor y majestuosidad de estos actos iban a depender de las posibilidades económicas de cada lugar, además de probar ante las otras poblaciones su poderío y hacer pública su expresión de lealtad y acatamiento al nuevo monarca.

El pregonero anunciaba por la ciudad y a viva voz la luctuosa noticia. Iba acompañado por un personaje que tocaba el tambor y por el escribano quien parecía certificar que lo manifestado era cierto. Atrás de ellos un piquete de soldados refrendaba la veracidad del anuncio. Toda la ciudad estaba atenta y se acercaba a escuchar la fecha oficial para el festejo.

En todos estos actos públicos existía como denominador común la celebración religiosa, ya que invocar a Dios se identificaba con una forma de redención hacia el monarca. Durante la misa una alta autoridad eclesiástica del lugar o de afuera, que podía ser del clero secular o el regular, a quien generalmente se le pagaba, proclamaba en un extenso sermón las virtudes del monarca. A veces ese sermón se publicaba. Luego venían los responsos por el difunto en medio de una escenografía acorde donde abundaban las velas, el incienso y la música fúnebre que ayudaban a crear el ambiente de tristeza y devoción.

En tal sentido proliferó una legislación que tenía en cuenta todo lo concerniente al ceremonial, vestuario, formas de actuar, etc. Por su parte la representación del entierro real, como máxima demostración de la reverencia hacia el difunto de acuerdo a su rango, señalaba la sacralización física del ámbito urbano. El ingrediente ritual y esa exteriorización del culto resuelto en forma procesional hacían transformar la ciudad, especialmente su Plaza Mayor, en un ámbito cambiante y adaptable a diversas circunstancias de la vida cotidiana. Pero siem-

\footnotetext{
7 Daisy RíPODAS ARDANAZ, «El ingrediente religioso en las exequias y proclamaciones reales», $A r$ chivum, XVI (1994) p. 163.
} 
pre en el sentido de sacralizar una ciudad cuyos pobladores compulsivamente debían participar en forma activa. Tanto para el funeral como para la proclamación, el ritual del acto funcionaba como un acontecimiento que se palpitaba en el lugar como si ocurriera allí mismo. Por ello tanto la misa de las exequias o el juramento de fidelidad al nuevo rey corresponden a la visión tradicional del poder emanado de Dios, pues quienes lo detentan son responsables ante Él. Así por ejemplo el Tedeum es un agradecimiento al Creador que forma parte del acto sacramental, cuyo testigo es Dios. El objetivo principal es el de representar el poder del rey sin reemplazar su persona.

Frente a estas consideraciones remarquemos que se presentan básicamente dos tipos de celebraciones diferentes. Por un lado la que hace referencia a la muerte del monarca y por otro la del regocijo de asunción de su heredero. Para las celebraciones fúnebres se montaba un amplio operativo donde se desarrollaba una arquitectura efímera que, en ocasiones, era sumamente magnificente. El elemento arquitectónico de mayor importancia lo constituía el túmulo ${ }^{8}$, cuya temporalidad era evidenciada en los mismos materiales con que se construía: estuco, madera, telas, etc. Su sencilla estructura era de madera, a modo de baldaquino, con un cielorraso de color negro. La decoración aludía a figuras pintadas o esculpidas, con emblemas e inscripciones alegóricas, donde la figura del rey debía ser realzada por todos los medios ofrecidos por la tradición heráldica y emblemática. Se podían leer en ellos varias filacterias que se relacionaban con el personaje y con versículos de la Biblia resaltando el triunfo del arcángel del Juicio Final sobre la muerte y la poca importancia que tenían las jerarquías frente al fin de la vida.

El túmulo se ubicaba en el crucero de la iglesia mayor o catedral, incluso en ocasiones en otras iglesias, frente al altar y sirviendo de marco o envolvente de

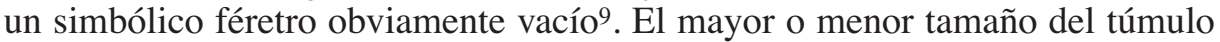
no indicaba la posición social del difunto sino que lo hacía la abundancia y calidad de las velas que se colocaban y que ocasionaban el mayor gasto de la cele-

\footnotetext{
${ }^{8} \mathrm{El}$ origen de los túmulos no era en el período colonial muy remoto ya que, según Antonio Bonet Correa, quien estudió sobre todo los levantados al emperador Carlos V, manifiesta que éstos se construyeron por primera vez en España entre 1539 y 1549. Fue Felipe II quien dictó una serie de disposiciones para cumplir en las principales ciudades del imperio a fin de honrar la muerte de su padre acaecida el 21 de setiembre de 1558. Paralelamente fue muy común que en muchas ciudades se imprimieran libros funerarios que no sólo describen las exequias, sino que también le incorporan grabados de túmulos (Antonio Bonet CorreA, «Túmulos del Emperador Carlos V», Archivo Español del Arte XXXIII (1960) p. 67). No obstante López Cantos recuerda que su origen, aunque limitado a los sepulcros monumentales de piedra o mármol, debe buscarse en Francia en el siglo XIII, generalizándose al resto de Europa en el transcurrir de los siguientes dos siglos. La primera noticia que de ellos se tiene en España es con las exequias del infante don Alonso en 1365 (López CANTOS, Juegos, fiestas y diversiones..., p. 129).

${ }^{9}$ Lorene PouncEY, «Grabados de túmulos peruanos», DANA, 28/29 (1989-1990) p. 82.
}

Hispania Sacra, LXI

124, julio-diciembre 2009, 423-446, ISSN: 0018-215-X 
bración. La iluminación que producían actuaba como emblema de la luz de Cristo y del alma que no se apaga ${ }^{10}$.

Como tipología arquitectónica, el simulacro de una tumba real, constituyó el monumento efímero más importante que produjo el arte en la América Hispana, sobre otros como arcos triunfales, altares, columnas, construcciones para fuegos artificiales. Capaz de impresionar notablemente a las autoridades y al pueblo, el entorno de su emplazamiento contribuía a lograr una misticidad que se conseguía en un recinto diferente, ante el especial acondicionamiento de sus muros cubiertos de lienzos negros que soportaban emblemas, en medio de altas bóvedas donde hacían una pronunciada sombra titilante las cientos de velas allí colocadas.

Con estas representaciones iconográficas se cumplía con los objetivos de enseñar (docere), deleitar (delectare) y convencer, (movere) tal cual lo establecía la retórica clásica de Cicerón y Quintiliano ${ }^{11}$. Organizar estas composiciones demandó la realización de un programa iconográfico que acompañaba la elaboración de los sermones fúnebres, como mecanismo de la oratoria sagrada.

El gobernador intendente de Córdoba del Tucumán, marqués de Sobremonte, dictó a fines del siglo XVIII una serie de normas por las cuales se debía regir este tipo de celebraciones teniendo en cuenta la reglamentación dada en España e Indias, principalmente la Pragmática de 1565 y la Real Cédula del 22 de marzo de 1693 , referida al moderamiento del uso del luto y reducción de los costos de los festejos ${ }^{12}$, que fueron las que orientaron a muchas otras disposiciones tomadas en algunas ciudades.

Posiblemente el túmulo más importante del siglo XVII en América fue el levantado para Carlos V en México (1559) por Claudio de Arciniega en el convento de San Francisco, inspirado en las realizaciones granadinas de Pedro Machuca. El diseño de la capital de Nueva España será un verdadero modelo, incluso también el de María de Portugal levantado en Sevilla, donde se introduce novedosamente la representación de un complejo programa iconográfico. Bajo estos lineamientos se destacan los túmulos de Felipe III en Lima (1621) y los de Carlos III en ambas ciudades (1781).

La arquitectura de los túmulos se orientará a la verticalidad de cuerpos decrecientes con el empleo de uno o varios cuerpos superpuestos revestidos con

\footnotetext{
${ }^{10}$ María Jesús Mejías Álvarez, Las estampas de túmulos reales del AGI, Sevilla, Escuela de Estudios Hispano-Americanos - CSIC, 2002, p. 26.

${ }^{11}$ Adita Allo Manero, «La emblemática en las exequias reales de la Casa de Austria», Actas del I Simposio Internacional de Emblemática, Teruel, España, 1 y 2 de octubre de 1991, p. 16.

${ }^{12}$ Catálogo cronológico de Reales Cédulas, órdenes, decretos, provisiones, etc., referentes a América. 1508-1810, Buenos Aires, Impr. Biblioteca Nacional 1938, p. 104.
} 
elementos decorativos y luminosos ${ }^{13}$. Las principales capitales se darán el lujo de ostentar grandes monumentos a fin de satisfacer la monarquía y con ello poder ganar su consideración.

Las representaciones de túmulos que se publicaron se convirtieron en modelos y con ello se oficializaron, de allí que pocas variantes surjan entre unos y otros, excepto casos puntuales como el del pueblo de indios de Coatepec en las honras de Carlos II en 1701, donde el aporte del arte aborigen es predominante.

Los símbolos iconográficos alcanzan igual valor de importancia artística que su arquitectura y la de las mismas composiciones literarias de los sermones de las exequias. En general las decoraciones aluden a la exaltación del monarca fallecido y a sus virtudes, la reflexión sobre la muerte y la mitificación del sucesor al trono ${ }^{14}$. Se empleará un lenguaje complejo y erudito, tomado de la Biblia, de la mitología y de la literatura clásica, e incluso de la variada cantidad de libros sobre empresas editados en los siglos XVI y XVII ${ }^{15}$, que anuncian la especial formación humanista del diseñador.

Participaron renombrados arquitectos en sus diseños, como grandes pintores y escultores. A veces se convocaba a concursos de proyectos como el de Felipe III en Lima (1621) que obtiene Luis Ortiz de Vargas.

Lamentablemente para Córdoba, incluso y hasta donde sabemos para todo el virreinato del Río de la Plata, no se han conservado representaciones gráficas de los túmulos levantados en esta amplia región, aunque se hayan publicado algunas relaciones y sermones, favorecidos por el funcionamiento de la Imprenta de Niños Expósitos o de la misma Imprenta Real de Madrid. Ni en los impresos, ni en los manuscritos hemos encontrado estos clásicos dibujos que abundan en otras ciudades americanas. Pero no por ello vamos a descartar un tema sensiblemente olvidado en la historiografía artística rioplatense.

\section{Fallecimientos de los Reyes de la CASA de Austria}

En los siglos XVI y XVII Córdoba asistió a las celebraciones luctuosas de los cuatro últimos reyes de la Casa de Austria. Nos referimos a Felipe II que murió en 1598, Felipe III en 1621, Felipe IV en 1665 y Carlos II en 1700. Al

\footnotetext{
${ }^{13}$ Mejías Álvarez, Las estampas de túmulos..., p. 32.

14 José Javier AZANZA LÓPEZ, «Los jeroglíficos de Felipe IV en la encarnación de Madrid como fuente de inspiración en las exequias pamplonesas de Felipe V», en Rafael ZAFRA y José Javier AzANZA (ed) Emblemática áurea. La emblemática en el arte y la literatura del siglo de oro, España, Ediciones Akal 2000, p. 35.

${ }^{15}$ Entre ellos los de Andrea Alciato (1549), Cesare Ripa (1593), Juan de Borja (1680), Sebastián de Covarruvias Orozco (1610), Diego Saavedra Fajardo (1677), Francisco Núñez de Cepeda SJ.

Hispania Sacra, LXI

124, julio-diciembre 2009, 423-446, ISSN: 0018-215-X
} 
comenzar el siglo XVIII asumieron los Borbones con Felipe V, quien abdicó a favor de su hijo Luis I en 1724. Luego de su fallecimiento ocurrido a los siete meses, volvería su padre quien muere en 1746, sucediéndolo su otro hijo Fernando VI. A la muerte de éste en 1759, sucede Carlos III quien fallece en 1788 y con él tendremos el último monarca al que se le rindieron los solemnes lutos.

Desde el primero de los reyes al último aquí señalado, el boato y solemnidad de las celebraciones fueron en ascenso, al igual que los días establecidos para realizarlas, reflejando con ello un aumento en la necesidad de exteriorizar el poder a través de los símbolos. Es decir la utilización de la fiesta como «un vehículo de propaganda a favor del poder real», donde aparece la ocasión para que todos los grupos que son algo -o pretenden serlo- aprovechan para reafirmar su posición, y de esta manera mostrar simbólicamente la estructura y configuración de la sociedad que componen» ${ }^{16}$.

Los acontecimientos que sucedían en la casa real llegaban al Nuevo Mundo con una demora que en ocasiones alcanzaba el año. Incluso las noticias arribaban por otras vías antes que por el correo oficial. Una vez enteradas las primeras autoridades, por medio de una Cédula Real, daban a conocer a la población la novedad a través del pregón. Luego comenzaban a recibir el pésame de las instituciones civiles, militares, religiosas y gremiales, mientras se construía el túmulo. Tras aproximadamente nueve días de luto, se llevaban a cabo las solemnes exequias que eran el núcleo principal de la luctuosa celebración. Duraban dos días, en el primero y por la mañana tenía lugar el acto protocolario del pésame y por la tarde las autoridades y la ciudadanía se trasladaban al templo, donde se había levantado el túmulo, a rezar las vísperas y la oración fúnebre en latín. El segundo día era la solemne misa que incluía el sermón panegírico que exaltaba las virtudes del difunto.

De la muerte de Felipe II, ocurrida en El Escorial en 1598, no se han conservado documentos que indiquen el tipo de actos que se llevaron a cabo, ni la iglesia elegida, para una ciudad que contaba con tan solo 40 vecinos y 6.000 indios, según la famosa Relación de Pedro Sotelo Narváez ${ }^{17}$.

La primera noticia, aunque escasa, que hemos encontrado sobre exequias reales es la que se hizo a la reina Margarita de Austria, fallecida en 1611, cuando daba a luz su séptimo hijo. El Cabildo decretó el luto ${ }^{18}$, pero las honras se

\footnotetext{
${ }^{16}$ Roberto J. LóPEZ, «La imagen del rey y de la monarquía en las relaciones y sermones de las ceremonias públicas gallegas del Antiguo Régimen», en Manuel NúÑEZ RodRíGUEZ (edición a cargo), $E l$ rostro y el discurso de la fiesta, Semata, ciencias sociales e humanidades, Universidad de Santiago de Compostela 6 (1994) pp. 200-201.

${ }_{17}$ Carlos S. A. SEgReti, Córdoba ciudad y provincia (siglos XVI-XX), según relatos de viajeros y otros testimonios, Córdoba, Centro de Estudios Históricos, 1998, p. 25.

${ }^{18}$ AC, V, 1609-1623, Córdoba, 1884, p. 289.
} 
realizaron en la iglesia de la Compañía de Jesús, no siendo casual, ya que la esposa de Felipe III había sido educada por jesuitas en su país natal. Así lo informó el padre provincial Diego de Torres SJ a su superior en 1614:

«Al fin, antes que volviesen los Padres a sus respectivas residencias, hice, según fue mandado por cédula real, celebrar solemnes exequias por el alma de las difunta reina Margarita, madre muy afecta de la Compañía. La oración fúnebre estaba a cargo del Padre Diego González. Holguín, muy bien preparada, la única con esta ocasión, y muy laudatoria para la Reina»19.

El padre Torres aprovechó la presencia de cuarenta sacerdotes que habían venido a Córdoba a celebrar la Congregación Provincial. Debe haberse construido un catafalco pero más interés para el informe fue hacer una referencia a la composición fúnebre que tuvo a su cargo este prestigioso jesuita ${ }^{20}$.

En cuanto para la muerte de Felipe III, ocurrida el 31 de marzo de 1621, luego de notificado, el Cabildo fijo el 7 de marzo de 1622 para el inicio de los actos. También envió a dos alcaldes y a dos regidores para que recorrieran los conventos de la ciudad comunicando la noticia y solicitando se cantaran misas en sus iglesias. Finalmente se participó al vicario a quien se invitó a tocar las campanas durante las honras y se solicitó al padre Diego de Torres, provincial de la Compañía de Jesús, que predicara el sermón de las honras ${ }^{21}$. Es importante destacar que el honor de leer la oración fúnebre estaba reservado a los miembros del clero regular o secular de mayor prestigio de la ciudad 22 . El padre Torres (1551-1638) fue una figura fundamental en la historia de la Compañía de

${ }^{19}$ Carlos Leonhardt SJ, Documentos para la historia Argentina. Iglesia. Cartas anuas de la Provincia Jesuítica del Paraguay, Chile y Tucumán, de la Compañía de Jesús. 1609-1614, XIX, Buenos Aires, Facultad de Filosofía y Letras. Instituto de Investigaciones Históricas 1927, pp. 390 a 423.

${ }^{20}$ El padre Diego González Holguín nació en Cáceres, España, en 1553. Ingresó a la Compañía de Jesús de Toledo en 1571. Posteriormente se traslada a América, haciendo sus últimos votos en Quito en 1588. Al Paraguay pasa en 1608, falleciendo en Mendoza en 1617. Fue rector del colegio de Asunción y comisario de la Inquisición. Destacándose como estudioso de las lenguas indígenas, fue autor de la gramática quichua (1607), e intentó hacerlo también con la lengua guaraní, cuyos estudios seguramente fueron tomados luego y por ejemplo por Antonio Ruiz de Montoya.

${ }^{21}$ Seguramente el padre Torres informó de este acontecimiento a su superior en Roma a través de la Carta Anua correspondiente. Pero se desconoce esta pieza documental que podría haber ampliado las referencias sobre nuestro tema, extendiéndose esta ausencia entre los años 1619 y 1626 que son los que publica el padre Carlos Leonhardt SJ en 1929.

${ }^{22} \mathrm{Al}$ respecto Rípodas Ardanaz señala que en Buenos Aires para las honras de Felipe III predicó el obispo carmelita Pedro de Carranza, en las exequias de Felipe V lo hicieron los jesuitas Pedro de Arroyo y José Barreda, para Carlos III el franciscano José de Parras. Todos ellos distinguidos y notorios prelados. Podemos agregar que, para el caso de Córdoba, en el ex Instituto de Estudios Americanistas, se encuentran una oración panegírica de Luis XIV de Manuel Antonio de Frías compuesta en 1715 y el sermón fúnebre que se envió a Córdoba y que escribió el jesuita Carlos Miñano el 14 de marzo de 1714. (RÍPODAS ARDANAZ: «El ingrediente religioso», p. 166).

Hispania Sacra, LXI

124, julio-diciembre 2009, 423-446, ISSN: 0018-215-X 
Jesús en la Provincia Jesuítica del Paraguay. Había arribado a Córdoba en 1607 destinando a Córdoba como cabecera de una amplia jurisdicción. Como tal, una de sus primeras medidas fue la de crear el Colegio Máximo, convertido luego en la primera universidad argentina. Pero fundamentalmente al padre Torres se deben las bases para la creación de los pueblos jesuítico-guaraní con la fundación de la primera reducción de San Ignacio Guazú, entre otras.

En la misma sesión capitular se establece que la comitiva, tanto en las vísperas como para la misa, partiría desde el Cabildo con sus cabezas cubiertas. Lo harían en hilera de dos en dos, desde el justicia mayor, alcaldes y capitulares por su antigüedad, y finalmente los vecinos y moradores de la ciudad.

El Cabildo de Córdoba tomó una serie de disposiciones con respecto a la construcción del túmulo y solemnidades a realizarse en la iglesia mayor y los conventos, como la obligatoria participación de los funcionarios del Cabildo. De tal manera, manifestaba la institución que el túmulo:

«sea alto y levantado sobre gradas y tablado con su tunba en el alto con un cuxin y una corona en medio y un estoque y un estandarte dignos dos negras y las hachas y cera menuda que fuere necesaria conforme al tumulo el qual ade ser todo de paños negros y en la frente de la tumba se pongan las armas rreales».

Se encargarían de ejecutar las obras los alcaldes ordinarios y don Luciano de Figueroa depositario general y Francisco Mexía regidor perpetuo ${ }^{23}$.

Esta es la primera descripción con que contamos de una conmemoración luctuosa en Córdoba. Sin embargo es pobre de información acerca del túmulo, ya que no menciona el autor, ni detalles del mismo. Sólo se da cuenta de algunos elementos simbólicos comúnmente utilizados en túmulos como, además de las armas y estandarte real, el cojín y la corona que representan la monarquía y las hachas el poder de la luz.

El reinado de Felipe IV se caracterizó, como ningún otro, por la abundante cantidad de fiestas cortesanas ofrecidas por el monarca. Alegría, despilfarro y bullicio por cierto contrastaban con la miseria pública, los reveses militares y políticos que paulatinamente arrastrarían a España a su decadencia ${ }^{24}$. Obviamente el suntuoso lujo de la corte más poderosa del mundo no se repitió en otras regiones y mucho menos en colonias tan distantes como la nuestra. Pero lutos y casamientos signaron una manera de celebrar acontecimientos particulares de la realeza a los que se adhirió sin vacilar.

Uno de esos lutos fue por ejemplo el de la reina Isabel de Francia quien fallecía el 6 de octubre de 1644, mientras el rey Felipe IV se encontraba en Zara-

${ }^{23}$ AC, VI, 1619-1623, Córdoba, 1884, p. 245.

${ }^{24}$ José Deleito y Piñuela, Madrid, El rey se divierte, Alianza Editorial 1988, p. 162. 
goza preparando la guerra de Cataluña alentada por Francia. La noticia llegó a Córdoba y fue leída en la sesión del Cabildo del 5 de septiembre del año siguiente. La carta era del gobernador, quien ordenaba:

"por lo que toca a esa ciudad ustedes mandaran luego que rrescivan esta publicar que todos los vecinos della pongan luto y se hagan las obsequias y onras acostumbradas $y$ devidas a tan justo sentimiento».

Pero como la mayoría de los capitulares estaba fuera de la ciudad se mandó a llamarlos para acordar el día y forma de llevar adelante el mandato. La próxima sesión, del 2 de octubre:

«se acuerda por boto y paresceres de todos la forma del tumulo y de donde se a de costear e los oficiales y peones del y adorno de bayeta negra sera ynsinias rreales y corona y setro y masas y demas aderentes necesarios y que se asigne y señala el dia en que se ha de hacer para que dos diputados los que nombrare este cabildo en su nombre se lo hagan saber al señor dotor adrian cornejo cura y vicario para que su merced con todos sus eclesiásticos acudan las visperas y dia de onrras a los oficios y para que ansi mismo lo hagan saber a todos los prelados de las rrelixiones para que con sus comunidades acudan y ansi mismo para que asistan antonio Ferreira maestro escultor a quien esta cometido la fabrica del tumulo».

Finalmente acordaron que el lunes próximo serían las «exequias y honras» y el martes las «exequias» en la iglesia parroquial ${ }^{25}$.

Tendremos en este caso el nombre del autor del túmulo a quien en otro párrafo se lo señala como «maestro arquitecto». Este parece ser el mismo que, junto a varios técnicos de la ciudad, fueron convocados en 1646 por el Cabildo de Córdoba para que emitiera su opinión en la construcción de un dique y acequia que se pensaba construir pues «sabe y entiende de tales obras» ${ }^{26}$.

$\mathrm{Al}$ poco tiempo se sumó la muerte del príncipe Baltasar Carlos, hijo del rey Felipe IV. El heredero del trono frisaba los 17 años y recién había contraído matrimonio con su prima la archiduquesa Mariana de Austria de tan sólo 14 años de edad. Una indisposición en vísperas del aniversario del fallecimiento de su madre fue la causante de su muerte, ocurrida el 9 de octubre de 1646. No obstante la fecha del deceso, recién en la sesión del 16 de abril de 1648 el mismo gobernador Gutierre de Acosta y Padilla leyó la Cédula Real que el rey firmaba en Zaragoza casi dos años antes. Lo hicieron todos respetuosamente parados y con sus cabezas descubiertas y una vez leída pasó de mano en mano por los cabildantes quienes la besaron. En ella solicita que todos se vistan de luto y

${ }^{25}$ AC, IX, 1643-1650, Córdoba, 1952, pp. 228 a 229.

${ }^{26}$ Guillermo FuRLONG SJ, Arquitectos argentinos durante la dominación hispánica, Buenos Aires, Editorial Huarpes 1945, p. 71.

Hispania Sacra, LXI

124, julio-diciembre 2009, 423-446, ISSN: 0018-215-X 
rindan las honras y demostraciones, similares a las que se hicieron con la reina, fijándose el día 27 de ese mes ${ }^{27}$.

Venimos tratando las distintas ceremonias realizadas durante el reinado de Felipe IV y la última fue su propio funeral acaecido en 1665. Las Actas del Cabildo nada dicen al respecto, pero la documentación que nos ilustra son las Cartas Anuas de los jesuitas, ya que las exequias se realizaron en su iglesia. Efectivamente en la carta que escribe en 1667 el provincial Andrés de Rada al general Pablo Oliva le cuenta que:

«Tan pronto que llegó acá el aviso oficial de la muerte de Don Felipe IV, Rey de España, ordené que cada uno de nuestros sacerdotes ofreciese tres misas para el eterno descanso del ilustre difunto, esperando otras disposiciones de parte de Vuestra Paternidad; además se apresuró el Colegio a celebrar solemnísimos funerales para el Rey, insigne bienhechor nuestro, levantando un gran catafalco, rodeado de velas de cera y adornado artísticamente con las insignias reales, y cargado con piezas literarias alusivas a este luto, escritas caligráficamente, con arabescos y miniaturas, así que todo el aparato alcanzó casi hasta la bóveda. Asistieron a estos funerales, como testigos de nuestro respeto y nuestra gratitud para con el Rey, los oficiales Reales, el clero y el claustro universitarios y un numeroso gentío. Cantóse un Requiem polífono e hízose un discurso fúnebre, quedando el auditorio muy satisfecho de estos últimos honores a su Rey»28.

Esta descripción alude a la existencia de elementos antes no mencionados como son los lemas o «piezas literarias». Estas composiciones poéticas podían servir para explicar un emblema, constituyéndose en particulares conjuntos plástico-literarios, concebidos «sobre la indisolubilidad de la palabra y la imagen» 29 . En cuanto a las dimensiones del túmulo, aparentemente fueron considerables ya que se escribe que llegaba casi hasta la bóveda, cuya medida hasta el arranque es de diez metros. No se menciona el autor del proyecto artístico-arquitectónico, ni quien compuso esas «piezas literarias», ni la oración fúnebre, pero descartamos que fueron seguramente miembros de la Compañía de Jesús, a la que no le faltaban talentos para estas realizaciones.

Un tanto diferentes fueron los actos del fallecimiento del último de los Austria, «el hechizado», pues luego de transcurrir un período de gobierno lleno de desventuras para el joven rey, murió el $1^{\circ}$ de noviembre de 1700 a los 39 años de edad. El Cabildo de Córdoba estaba en una situación económica delicada y le costó gran sacrificio el gasto de la cera para las cien velas de una libra, veinte antorchas de dos libras y doscientas cincuenta velas de mano, que durante una semana de agosto de 1701 alumbraron el túmulo del rey.

\footnotetext{
${ }^{27}$ AC, IX, 1643-1650, Córdoba, 1952, p. 532.

${ }^{28}$ Biblioteca del Colegio del Salvador (BS), Cartas Anuas, 1667, Estante 11, f. 157v.

${ }^{29}$ Allo Manero, «La emblemática...», p. 23.
} 
Igual fue el esfuerzo que demandó la jura del rey Felipe $\mathrm{V}$ en febrero del siguiente año, aunque no faltaron los vocablos deslumbrantes y el despliegue de terciopelos, cojines y doseles que contrastaban con la empobrecida ciudad, con su polvorienta y calcinada Plaza Mayor del verano mediterráneo ${ }^{30}$.

\section{El SIGLO XVIII, LOS BORBONES Y LAS EXEQUiAS DE CARLOS III}

En el caso del fallecimiento del rey Felipe V, ocurrido repentinamente en el Real Sitio y Retiro del Prado el sábado 9 de julio de 1746, su propio hijo, como era costumbre, anunció su deceso por Real Cédula del 13 de julio de ese año manifestando que:

«en ocasión de tanto dolor y sentimiento pasar a hacer demostraciones que correspondan a sus fineza; y porque es justo que estas (sin faltar a lo preciso para la decencia se moderen en todo lo posible».

Agregó que los lutos se deberían hacer de acuerdo a las disposiciones de la Cédula del 22 de marzo de $1693^{31}$.

No poseemos mayor información sobre los acontecimientos sucedidos con las muertes de Luis I y Fernando VI, ni de algún miembro de la familia real, excepto la comunicación enviada al obispo del Tucumán en que Felipe V lo participa el 28 de setiembre de 1724 notificando la muerte de Luis ${ }^{32}$. No obstante las honras y exequias de Carlos III se encuentran detalladamente documentadas, incluso publicadas ${ }^{33}$, y nos pueden dar una idea más cabal de este tipo de celebraciones realizadas en Córdoba del Tucumán.

Es necesario señalar que durante el mandato de Carlos III aconteció la muerte de su esposa María Amalia de Sajonia ocurrida el 27 de setiembre de 1760.

${ }^{30}$ Carlos A. Luque Colombres, «La Córdoba de los siglos XVI, XVII y XVIII a través de las actas del Cabildo». Guía de Córdoba Cultural, 2 (junio de 1980) p. 36.

${ }^{31}$ Museo Mitre. Documentos de su archivo colonial, 1514-1810, 1746 A:B-C.18, Nº 10.

32 Centro de Investigaciones de la Facultad de Filosofía y Humanidades, ex Instituto de Estudios Americanistas (en adelante IEA), Doc, $\mathrm{N}^{\circ} 6563$.

${ }^{33}$ Firmado por Francisco Martínez Villamil y con el título de: «Sentimientos leales de ternura que la Provincia de Córdoba del Tucumán, Virreinato de Buenos Aires, manifestó en el fallecimiento de su Católico Monarca el Señor D. Carlos III y regocijo en la exaltación al trono de su augusto hijo y sucesor el Señor Don Carlos IV (que Dios guarde) con su dignísima esposa la reina nuestra señora Da. Luisa de Borbón», apareció en una de las primeras publicaciones generalistas de España surgida en 1784 llamada Memorial literario, instructivo y curioso de la Corte de Madrid, en el N$^{\circ} 110$, Tomo 20, pte. $2^{a}$ de mayo de 1790. En la Real Imprenta de Niños Expósitos se publicó en 1783 el sermón del deán Gregorio Funes con el título Oración fúnebre que en las exequias del católico Rey D. Carlos III celebradas en esta Santa Iglesia Catedral de Córdoba del Tucumán dijo el Dr. D. Gregorio Funes, canónigo de merced de la misma Iglesia.

Hispania Sacra, LXI

124, julio-diciembre 2009, 423-446, ISSN: 0018-215-X 
Poco más de un año después se recibió la noticia en Córdoba, para lo cual los miembros del Cabildo hicieron publicar en la «plaza pública en forma de bando a son de caja de guerra y voz de pregonero en concurso de mucha gente», el despacho del virrey para que todos se vistan de luto y se hagan las correspondientes exequias y sufragios para el 8 de febrero de $1762^{34}$. Este notable retraso fue aparentemente común en otros sitios como en Lima que se efectuaron el 26 de junio de 1761 o Filipinas el 2 de diciembre de ese año.

El fallecimiento de Carlos III, aconteció en la madrugada del domingo 14 de noviembre de 1788. Sus restos fueron expuestos en el Salón de Embajadores del Palacio Real de Madrid. Se levantó un gran monumento funerario construido por Antonio González Velásquez ${ }^{35}$. El miembro de la Real Academia de San Fernando siguió los gustos neoclásicos, siendo también quien proyectó el túmulo de la ciudad de México, donde era director de la Academia de San Carlos ${ }^{36}$.

La necrológica notificación que circuló por América y Filipinas la firmaron Antonio Valdés y Antonio Porlier el 23 de diciembre, señalando para que «el pueblo se enterase de la desgracia ocurrida y celebrase los sufragios acostumbrados a las personas reales» ${ }^{37}$.

La nota la recibió el virrey marqués de Loreto e inmediatamente ordenó que circulara la noticia entre autoridades civiles y religiosas. En la capital del virreinato se fijó fecha 29 y 30 de julio de 1789 y se encargó el túmulo al ingeniero brigadier José Custodio de Saa y Faría ${ }^{38}$ para que lo construyera en la iglesia catedral, cuyo costo se elevó a la suma de 1.400 pesos.

${ }^{34}$ AHC, Gobierno, caja 4, carp. 3, exp. 35.

${ }^{35}$ Lo citamos particularmente porque Antonio fue el padre del artista Zacarías González Velázquez, quien en 1795 pintaría para Córdoba cuatro excepcionales lienzos representando a Nuestra Señora de Nieva o la Soterránea. Zacarías nació en Madrid en 1763, estudiando en la Academia de Bellas Artes de San Fernando, donde obtuvo premios en 1778 y 1781, además de ser elegido académico de mérito en 1790. Fue autor de cartones para tapices, retratos, frescos y asuntos religiosos, en 1801 fue designado Pintor de Cámara por el rey Carlos IV. En 1819 fue nombrado Director de Pintura de la Real Academia de San Fernando, llegando a ser Director General de la misma en 1828. Falleció en Madrid el 31 de enero de 1834 (Bertha NúÑEZ BERNIS, Zacarias González Velásquez, 1763-1834, Madrid, Editorial Doce Calles, 2000. Ramón Gutiérrez y Carlos PAge, La Catedral de Córdoba, Córdoba, Fundación Centro, 1999).

36 Ramos Sosa, Rafael, «Los túmulos de Carlos III en Hispanoamérica. México, Lima, Santiago de Chile y Valparaíso». Cuadernos de Arte Colonial. Museo de América, 6 (1990) p. 33.

${ }^{37}$ José, TORRe REVEllo, «Crónicas coloniales. Exequias fúnebres por Carlos III y fiestas de proclamación de Carlos IV en algunas ciudades del Virreynato del Río de la Plata», La Nación (29 de mayo de 1927). También y del mismo autor Crónicas de Buenos Aires Colonial, Buenos Aires, Ed. Bajel, 1943.

${ }^{38}$ El destacado ingeniero militar no sólo era portugués sino que había sido derrotado y arrestado por el virrey Cevallos, quien le reconoció sus dotes profesionales y le permitió radicarse en Buenos Aires donde vivió y murió en 1792. Construyó obras de carácter religioso y civil, como la Catedral de Montevideo y otras tantas iglesias uruguayas. En Buenos Aires se ocupó de su aspecto urbanístico y proyectó obras importantes como la fachada de la Catedral, la plaza de toros, etc. (FurLong, Arquitectos argentinos..., p. 255). 
La noticia también fue comunicada al resto de las gobernaciones. A Córdoba llegó en el mes de marzo y fue directamente dirigida al gobernador Sobremonte por el sucesor de la Corona quien también remitió otra al obispo del Tucumán para que procediera a hacer los honores y exequias, ambas fechadas en Madrid el 24 de diciembre de $1788^{39}$. El gobernador Sobremonte ordenó el ritual del rugir de cañones y tañido de campanas en una particular conmoción de ruidos que eran parte del programa sobre el acontecimiento. Incluso y también como era habitual y señalamos anteriormente para otra celebración fúnebre, el pregonero que circulaba por las calles junto al escribano y un grupo de soldados que llamaban la atención de la gente con sus tambores y pífanos.

El Cabildo, por su parte, ordenó al ingeniero voluntario Juan Manuel López que levantara un túmulo en la Catedral y en honor al monarca desaparecido. Efectivamente, además de la construcción y reparación de templos, capillas, fortines, casas de particulares etc. el ingeniero López, era a quien se acudiría cuando se necesitaba erigir arcos de triunfo, tablados para representaciones escénicas, etc. Su obra en Córdoba fue destacada y aunque no fue un profesional formado, su capacidad le valió la distinción de «Ingeniero voluntario» por Real Cédula suscripta en Aranjuez el 18 de febrero de 1794. Vizcaíno de origen, naciendo en 1748 y llegando al Río de la Plata en 1763, fue comerciante. Murió en 1813 en Córdoba, donde residió y trabajo gran parte de su vida ${ }^{40}$.

El túmulo fue descripto detalladamente en 1789 por el escribano Martín de Arrascaeta, quien señalaba:

«El túmulo se levantó sobre una figura circular de tres pies de altura, y veinte y seis de diámetro, con cuatro altares que se erigieron por cada uno, ocupando los intermedios, ingeniosos lemas, y elegantes sonetos, que panagenizaban las virtudes del difunto Monarca; en medio del tablado se elevaba un hermoso pedestal de Orden Corintio, con cartelas en los cuatro ángulos, sobre un sócalo, que figuraban las cuatro mesas de altar. El pedestal era de quince pies de altura, sobre sócalo, y en el dado, o neto de este, se hallaban cuatro lapidas de color papiro, recibiendo la del frente, el escudo de las Reales Armas, y la inscripción sepulcral del Soberano, a quien se dirigía las otras tres lapidas de los frentes restantes, contenían cada una, un lema, y soneto; y sobre el pedestal sentaba una urna cinericia de ocho pies de altura, adornada con recuadros, perfiles y dibujos, rematando en un almohadón de terciopelo galoneado, que recibía la Corona, y Cetro Real; siendo la total elevación de dicho túmulo, treinta y cuatro pies, y hallándose a los cuatro ángulos del pedestal, cuatro obeliscos de diez y ocho pies de elevación bien adornados de luces, hasta rematar en una» ${ }^{41}$.

${ }^{39}$ IEA, Docs. 11.274 y 6834.

${ }^{40}$ FurLong, Arquitectos argentinos..., p. 259.

${ }^{41}$ Archivo General de la Nación Argentina (en adelante AGN), Sala IX, 5-9-7.

Hispania Sacra, LXI

124, julio-diciembre 2009, 423-446, ISSN: 0018-215-X 
Los detalles aquí transcriptos resultan difíciles de representar gráficamente, incluso de encuadrarlo estilísticamente. Pero podemos destacar las dimensiones de este túmulo de curiosa planta circular, de siete metros y medio de diámetro y con una altura total de diez metros. Sobre el pedestal, flanqueado por cuatro altos obeliscos, se colocó la urna de más de dos metros de altura ricamente decorada y rematada por un almohadón de terciopelo galoneado donde se apoyaba la corona y el cetro real.

Cuatro lápidas se ubicaron en sus lados, anotándose en la del frente la inscripción sepulcral del soberano con su escudo y armas reales, mientras que las otras llevaban textos con lemas y sonetos alusivos a las virtudes del monarca, como se venía realizando en estos monumentos desde el siglo XIV en Italia. Una transcripción de esos textos se ha conservado e insertamos como apéndice por ser la única pieza literaria, en esta tipología, que se ha conservado del Río de la Plata, muy posiblemente redactada por el deán Gregorio Funes. Basamos esta afirmación en que el deán estaba ligado a la organización del acto y era una persona a la que se le consultaban estos temas. Así como redactó el sermón de las exequias, también sabemos que redactó la placa que en honor a Carlos III se hizo sobre la inauguración de la fuente de la alameda.

En el túmulo se había colocado un retrato del rey, realizado por el artista Manuel Javier Garay. En la pintura, que no se ha conservado, se podía observar «una ninfa recostada sobre las armas de Córdoba, cuyo rostro acreditaba infinita tristeza»; en lo alto, entre nubes y rumbo al Paraíso, se contemplaba la figura del desaparecido rey Carlos III ${ }^{42}$. Garay posiblemente pudo haber participado en otras decoraciones debido a su renombrada actuación artística en aquellos días. Recordemos que fue el artífice fundamental de las obras de la Catedral que se realizaban por entonces en Córdoba. Sabemos de él que era pardo, nacido en Córdoba en 1752 y fallecido en 1820. Fue el autor del proyecto de la custodia de plata que se conserva en el templo de San Francisco, donde incluso se guarda un dibujo a tinta que certifica su autoría, fechado el 31 de enero de 1805. Pero se lo conoce mayormente por su intervención en el altar de la Soterránea o Nuestra Señora de Nieva, ubicado en la iglesia catedral, donde fue asistido por el carpintero Inocencio y tres oficiales, empleando siete meses de ardua labor. En el singular altar luego se colocó una imagen de la virgen traída de España y los cuatro cuadros que aluden a su vida realizados en 1795 en la Academia de Nobles Artes de San Fernando que mencionamos antes ${ }^{43}$.

\footnotetext{
${ }^{42}$ Luis Roberto, AltamIRA, Córdoba, sus pintores y sus pinturas (Siglos XVII y XVIII), Córdoba, Universidad Nacional de Córdoba, Facultad de Filosofía y Humanidades, Instituto de Estudios Americanistas 1954, p. 110.

43 GutiérreZ y Page, La Catedral..., p. 67.
} 
La Catedral se adornó para la ocasión siguiendo la tradición. Se colgaron de las paredes lienzos negros que, junto a una débil iluminación, creaban un clima lúgubre que sólo era medianamente suavizado con inscripciones insertas en paredes y en el propio túmulo cuyos emblemas exaltaban las virtudes del difunto. El edificio permaneció cerrado hasta el atardecer en que comenzó la solemne función religiosa presidida por el marqués de Sobremonte en carácter de gobernador-intendente, tal como se sugiere por la Real Cédula que a su vez acentúa la moderación que debía tenerse de lutos y túmulos pero sin faltar a la solemnidad del caso. Se concentraron todas las autoridades locales quienes ungidos de un profundo recato daban al gobernador las condolencias. Al otro día, a media mañana, se llevó a cabo el oficio luego del arribo del gobernador y su comitiva. En la ocasión el deán Gregorio Funes pronunció una memorable oración recordatoria. Una figura por demás relevante era este canónigo de merced, doctor en teología de la Universidad de Córdoba, y bachiller in utroque por la de Alcalá de Henares. En su composición establecerá un paralelismo de la vida del monarca con la de Josafat, rey de Judá. Cargado de citas bíblicas en latín, el texto tendrá como eje las virtudes del rey como gobernante y como cristiano. En ellas abundarán las precisiones históricas a las que estaba acostumbrado Funes ${ }^{44}$. Seguramente las gesticulaciones del deán causaron la esperada conmoción de un auditorio asombrado frente a las palabras manifestadas en el ámbito apropiadamente acondicionado.

El luto duró «seis meses de rigor y tres de alivio» como lo imponía la costumbre y ordenaba el virrey marqués de Loreto, siendo los tres primeros de estricto cumplimiento y señalándose la fecha del 3 de noviembre para celebrar la proclamación del nuevo rey Carlos IV.

De esta manera el dolor de la muerte real era totalmente revertido con la asunción del nuevo monarca, ceremonia que alcanzaba contornos mayores, precisamente por ser un hecho de regocijo. Obviamente ambos acontecimientos se sucedían en corto tiempo, recordemos que en junio llegaba la noticia del rey muerto y en septiembre ya se aprestaba el Cabildo a concretar los actos correspondientes a la ciudad. Se engalanó la estampa de la Plaza Mayor con ornatos efímeros que insinuaron un cambio de fisonomía, pero que tuvieron corta duración y la plaza continuó varias décadas con su primitivo aspec-

${ }^{44}$ Un análisis completo de lo manifestado por Funes, comparado con otros dos sermones realizados para la misma ocasión en otros sitios y tiempos, puede verse en RíPODAS ARDANAZ, «El ingrediente...», El sermón de Funes fue impreso en Buenos Aires en 1790 en la Imprenta de Niños Expósitos, con el título «Oración fúnebre que en las exequias del Católico Rey D. Carlos III celebradas en esta Santa Iglesia Catedral de Córdoba del Tucumán dijo el Dr. D. Gregorio Funes...». Existe una copia en el AGN, División Colonia, Sección Gobierno, Intendencia de Córdoba 1788-1790, Sala IX, 5-9-7 y otra en el IEA. Doc. No 6.414 y 6415 (borrador y original). Está reproducida en Archivo del Dr. Gregorio Funes, con noticia preliminar de Raúl Quintana, Tomo 1, Buenos Aires, 1944.

Hispania Sacra, LXI

124, julio-diciembre 2009, 423-446, ISSN: 0018-215-X 
to sin sospechar que nunca más se realizarían ceremonias luctuosas de la corona española.

Todos estos actos realizados en Córdoba motivaron al virrey Loreto para felicitar al gobierno local, manifestando al gobernador Sobremonte que:

«aplaude el esmero con que usted, ambos cabildos, alférez real, cuerpo de comercio, gremios y vecindario acudieron a completar la función con sus respectivas demostracio$n e s »^{45}$.

Posteriormente informó al rey sobre el esmero y fidelidad del pueblo cordobés.

Es muy probable que las celebraciones de Córdoba, tanto los lutos como la jura, hayan sido las más importantes, alcanzando mayor lucimiento que las de la misma capital del virreinato que comenzaron el 8 de agosto. De hecho fueron ampliamente conocidas en España a través de su publicación en el Memorial literario, instructivo y curioso de la Corte de Madrid.

\section{CONSIDERACIONES FINALES}

Las ceremonias fúnebres con sus gestos, vestuario y escenografía, acrecentaban los sentimientos y veneración a la enigmática figura real que representaba el poder, la autoridad y la justicia. Esta exaltación constituía en América un instrumento para arraigar y mantener vivas las costumbres de los colonizadores e insertar un modelo cultural en los indianos. Cohesionaba a todos los grupos sociales, a pesar que se evidencia una clara visualización de las jerarquías impuestas. La muerte era desafiada con la proclamación del heredero, asegurando la continuidad y sacralidad de la monarquía.

La presencia del túmulo semejaba la corporalidad del monarca en cada rincón de sus dominios. Pero no era sólo su arquitectura el instrumento de representación de estos conceptos. Si bien era el más importante, coadyuvaban el tratamiento general de la iglesia, la iluminación, decoraciones, emblemas y textos alusivos que contribuían a resaltar la figura del rey y sobre todo lo que simbolizaba.

El mayor boato dado al acto que, como señalamos, se incrementó a medida que trascurrieron los años de la colonia, también responde al crecimiento de la ciudad y su economía y que no se detuvo a pesar de la Cédula de Carlos II de 1693 sobre reducción de los gastos en este tipo de celebraciones, que no dejó de repetirse sucesivamente.

${ }^{45}$ AHC, Gobierno, Caja 11, carp. 10, exp. 10. 
Llegaba la noticia, se trataba en el Cabildo y generalmente se nombraba a dos de sus miembros para que se encargaran de la organización general de los actos. En todo este despliegue se incluía la designación del proyectista del túmulo y del compositor de las piezas literarias. Sólo conocemos dos autores de túmulos de Córdoba, el maestro arquitecto Antonio Ferreyra que realizó el correspondiente a la reina Isabel en 1644 y el ingeniero voluntario Juan Manuel López que construyó el de Carlos III. De este último túmulo también tenemos noticias de Manuel Javier Garay su posible decorador y los textos de las inscripciones panegíricas que tuvo y que transcribimos en el apéndice por los motivos antes señalados.

Los túmulos de Córdoba se construyeron generalmente en la iglesia mayor o en la Catedral, excepto el de la reina Margarita que se construyó en la iglesia de la Compañía de Jesús, seguramente a cargo de artistas de la Orden. No obstante en todos los templos se realizaban oficios religiosos por la muerte del monarca. Pero sólo en uno se levantaba el túmulo y era donde se realizaban las solemnidades de las exequias. En ese acto netamente religioso el momento más esperado era el sermón, confiado a personajes importantes de la ciudad. En el caso de Córdoba conocemos los de la reina Margarita, Felipe III y Carlos III que hicieron Diego González Holguín SJ, Diego de Torres SJ y el deán Gregorio Funes respectivamente. Este último creemos que también redactó las inscripciones que llevó el túmulo.

Quizás como ninguna otra manifestación del hombre, en la representación de la muerte real se vincula tanto la ornamentación ambiental, la arquitectura de los túmulos, la pintura y escultura que los mismos contenían, como la literatura escrita y representada casi teatralmente en el acto del sermón. Todo contribuye para expresar una idea y un sentimiento donde el rey es protagonista y el arte su mejor intérprete.

\section{APÉNDICE}

Inscripciones del Túmulo de Carlos III. Uno principal se redacta en latín acompañado, como se especifica, de la ninfa sobre el escudo de Córdoba. Luego se transcriben los cuatro lemas en castellano que llevó el túmulo a su alrededor. (IEA, Doc. $\mathrm{N}^{\circ}$ 6.674)

Inscripcion del Tumulo

Catholica Hispaniarum Regiu

Potentissimi Indiarum Imperatoris

Caroli III. Tumulum intuere viator

Hispania Sacra, LXI

124, julio-diciembre 2009, 423-446, ISSN: 0018-215-X 


\section{Carulus hie}

quem toti orbi

Populorum Omnium obtinuerant vota,

quem huie Monarchia,

Sublimer sud instituerant dotes,

quem inmortali imperio

Orbis felicitas, publica tranquilatas

ipsius merita,

In superos pietas, in subditos amor,

Superorum vota,

Religionis studium, fidei incolumitas,

de possebat eternum:

tantam ad Orbis carolum amitrentin ruinam,

cum obstupueris etexmim plange,

viator.

Tantorum malorum solatium exit gemitus,

amoris hoc Monumentum ingenu,

perennis gemitus holocaustum,

fidelissima Tucumanen is Civitas

ofert Cordova.

IIII. KAL. Mai Anno Domini 1789

Pintaras una ninfa, recostada sobre las armas de Cordova, triste, llorosa, y arriba al Rey, que sube al cielo entre nubes.

Aspicis ut jaceant strati, sine viribus artus, nec sin, qualis oram, sola sed vmbra mei?

vix trabo perese fanidia tetrica vite ipsaque sunt onere languida membra sibi lassa jacent capitris, nimio sub pondere cervix, sarcina sumtque manus, sareina suntque pedes, surgere nune meditor, sed languent pondere membra, atque mibi obsistem, non finit ire dolor. 
heu! quid agam, gravis ipsa mibi, moriensque facensque reque volens cursu, non tamen apta sequi? sistams et dum captum retinent ergastula corpus, te quo, no possum corpore, mente seguar, Si no puede mi cuerpo macilento seguir por su dolor nuestro camino.

\section{f. 2}

Jamas olvidara nuestro destino

Memoria, Voluntad, y entendimiento.

Lema respiecit finem.

La grandeza, el poder, y la Corona la parca las destruye, y descompone, pero el Rey, que en cielo su amor pone laurel inmarcesible se eslabona. Esta es verdad que Carlos nos abona en el modo que al tranze se dispone, porque en el otro mundo le corone, el que domina sobre toda zona. Si mi Dios! tu gran clemencia alcanse el Monarca Español, por quien lloramos, sin clamor, con que tiernos te rogamos, porque libre Señor, en paz descanse, $\mathrm{y}$ entre tus escojidos le tengamos.

\section{Lema Sedet sola}

¿Que lugubre aparato aquí se advierte?

¿Que suceso, tan nuevo aquí se admira?

¡Porque se eleva, tan obscura Pira entre las negras sombras de la muerte? Cordova te responde; ó; triste suerte! 
murio mi Padre, y mi amor respira, la lealtad, y respeto, con que mira los despojos que dexa el brazo fuerte. mi luto, y mi dolor, no hai que admirar pues explican mi pena sin segunda, mis sucesos son dignos de llorarlos; y porque sentimiento al Orbe infunda, sabras que ya murio mi Rey Dn Carlos mira pues, si mi llanto, bien se funda.

Lema difecerunt pre, lacrimis oculimei.

Diador español, deten el paso repara en los extragos de la muerte, y veras de tu Rey, ¡o dura suerte! que llegó de su sol, el triste ocaso, Llora, suspira, gime, este es el caso, f.3

en que tu lealtad, si bien lo advierte, ni podra por su fuerza contenerte, ni permitir al llanto ser escaso.

¡Perdida grande! ausencia muy sensible! Cordova la lamenta; el Rey no entero, ¡golpe cruel! ¡suceso el mas terrible! Murio mi Rey, el gran Carlos III $^{\circ}$ ¡Naufragara la España? Era temible. ¡Que recurso nos queda? Su heredero.

Lema ubi est mort victoria tua

La obras, las palabras, las sanciones, del arte militar la gran pericia, el zelo, la prudencia, la justicia admiraron en Carlos las Naciones, 
su pureza llebó las atenciones

de todos los vasallos, la milicia

recibio nuebas reglas, que codicia

la Europa toda, con imitaciones.

Un afable, modesto trato humano,

una innata piedad la mas gloriosa

un justo discernir con juicio santo, aun la muerte confiesa vergonzosa, las memorias que dexa el soberano, sus cenizas, no mas cubrio la Losa. 